\title{
Procesowo zorientowana kultura organizacyjna w organizacjach sektora publicznego
}

\author{
Liliana Hawrysz \\ Politechnika Opolska
}

Katarzyna Hys

Politechnika Opolska

\begin{abstract}
Procesowe podejście do zarządzania organizacją wiąże się z postrzeganiem rzeczy zorganizowanych jako zbiory zespołowych działań, powiązanych ze sobą w taki sposób, aby w ich rezultacie powstała wartość atrakcyjna dla nabywcy ${ }^{1}$. Jest ono alternatywą dla funkcjonalnego modelu organizacji. W podmiotach sektora publicznego, niejednokrotnie zdarza się, że rozbudowane struktury prowadzą do autonomizacji poszczególnych obszarów w ramach tych struktur, co nazywane jest efektem silosów. Poszczególne komórki nie koncentrują się na zrozumieniu klienta i dostarczeniu mu usługi zgodnej z jego aktualnym stanem potrzeb, ale zabezpieczają własny, wewnątrzwydziałowy interes. Prowadzić to może do wydłużania czasu realizacji kontraktów, zwiększenia kosztów działania i obniżenia elastyczność organizacji.
\end{abstract}

Słowa kluczowe: kultura organizacyjna, zarządzanie procesowe, sektor publiczny.

\section{Wstęp}

Sektor publiczny zarówno w Polsce, jaki poza jej granicami na przestrzeni ostatnich lat podlegał licznym przemianom. Wiele $\mathrm{z}$ nich związanych było $\mathrm{z}$ aplikowaniem koncepcji i metod zarządzania bezpośrednio z sektora prywat-

1 P. Grajewski, Procesowe zarzadzanie organizacja, Polskie Wydawnictwo Ekonomiczne, Warszawa 2012. 
nego $^{2}$. Zarządzanie procesowe jest właśnie jedną z takich inicjatyw ${ }^{3}$. Mimo, iż podejście procesowe znane jest już od czasów szkoły klasycznej, jego obecna postać w znacznym stopniu ewoluowała od tego czasu przyjmując postać BPM (Business Process Mangement) zarządzania procesami biznesowymi ${ }^{4}$. Wyewoluowanie koncepcji BMP szacuje się na lata dziewięćdziesiąte XX wieku, w następstwie takich popularnych koncepcji jak TQM i BPR ${ }^{5}$. Wielu autorów analizując koncepcję BPM skupia się przede wszystkim na jej twardych aspektach, takich jak struktura organizacyjna, rozwijanie procesów i wsparcie nowoczesnych technologii informacyjnych ${ }^{6}$. Bardziej holistyczne podejścia definiują proces jako rdzeń organizacji będący źródłem wszelkich jej aktywności, ale tylko wtedy, gdy jest wspierany przez pracowników ${ }^{7}$. W tym ujęciu szczególnie zaakcentowano rolę kultury organizacyjnej, która zdefiniowana jak kluczowy czynnik może przyczynić się zarówno do sukcesu jak i porażki zarządzania procesowego $^{8}$. R.Tregear i T. Jenkins z BPTrends identyfikując potencjalne różnice pomiędzy zarządzaniem procesowym w sektorze publicznym i prywatnym część z nich sklasyfikowali jako katalizatory, a część jako inhibitory. Kultura organizacyjna znalazła się w drugiej grupie czynników z uwagi na powszechną niechęć organizacji sektora publicznego do podejmowania ryzyka, mniej elastyczną strukturę organizacyjną, mniejszą motywację do zmiany ${ }^{9}$.

Procesowy charakter organizacji może ułatwiać zaangażowanie organizacyjne i współpracę poszczególnych jej członków, usprawniać komunikację wewnętrzną. Jest to konsekwencja lepszego rozumienia celów organizacji. Procesowo zorientowana kultura organizacyjna daje możliwość zwiększania

2 L. Heracleous, R. Johnston, Can business learn from the public sector?, "European Business Review" 2009, nr 4.

3 R. MacIntosh, BPR: alive and well in the public sector, "International Journal of Operations \&, Production Management" 2003, nr 3.

4 P. Grajewski, Procesowe zarzadzanie..., op. cit.

5 J. Brocke, T. Sinnl, Culture in business process management: a literature review, "Business Process Management Journal" 2011, nr 2.

6 T.R. Gulledge Jr, R.A. Sommer, Business process management: public sector implications, "Business Process Management Journal" 2002, nr 2; R. MacIntosh, BPR: alive and well in the public sector, "International Journal of Operations \&, Production Management" 2003, nr 3; F.O. Sentanin, F.C.A. Santos, Ch.J.Ch. Jabbour, Business process management in a Brazilian public research centre, "Business Process Management Journal" 2008, nr 4.

7 J. Jeston, J. Nelis, Management by Process: A Roadmap to Sustainable Business Process Management, Elsevier, Oxford, 2008, s. 4, cytuję za: J. Brocke, T. Sinnl, Culture in business process management: a literature review, "Business Process Management Journal" 2011, nr 2.

8 J. Brocke, T. Sinnl, Culture in business..., op. cit.

9 R. Tregear, T. Jenkins, Government Process Management: A review of key differences between the public and private sectors and their influence on the achievement of public sector process management, BPTrends, October 2007. 
odpowiedzialności za jakość i eliminowania postaw autonomicznych, dzięki zrozumieniu znaczenia wpływu poszczególnych składowych organizacji na osiągane przez nią rezultaty ${ }^{10}$. Dzięki procesowo zorientowanej kulturze w organizacjach sektora publicznego łatwiejsze może być katalizowanie zachowań pożądanych z punktu widzenia ich klientów, takich jak między innymi: elastyczność, otwartość, profesjonalizm.

Szansę na popularyzację podejścia procesowego $\mathrm{w}$ sektorze publicznym stanowi wynikający z Priorytetu V „Dobre rządzenie” Program Operacyjny Kapitał Ludzki i jego działania 5.1 Wzmocnienie potencjału administracji rządowej oraz 5.2 Wzmocnienie potencjału administracji samorządowej.

Celem artykułu jest ukazanie, iż procesowo zorientowana kultura daje organizacjom sektora publicznego możliwość lepszego zrozumienia aktualnych potrzeb klientów oraz ułatwia rozpoznanie nowych stanów, wynikających ze zmian tych potrzeb. W artykule przyjęto założenie, iż kultura organizacyjna jest jednym z istotniejszych czynników determinujących zarządzanie procesowe w organizacji. Zastosowana metoda badawcza to analiza literatury przedmiotu.

\section{Zarządzanie procesowe administracji publicznej}

Organizacje sektora publicznego stanowią bardzo istotny element gospodarki kraju, mając jednocześnie wpływ na życie każdego mieszkańca. Ich wyróżnikiem jest: racjonalność polityczna i społeczna, nie zawsze utożsamiana z rachunkiem ekonomicznym, strategie działania będące konsekwencją logiki gry politycznej dominującej koalicji, trudność w wyznaczaniu celów działania o efekcie słabo mierzalnym i długiej perspektywie czasowej, trudność w określaniu efektów działań w zakresie zaspokajania dóbr publicznych i społecznych, kadencyjność władz utrudniająca myślenie strategiczne i powodująca koncentrację na krótkim horyzoncie czasowym oraz mająca wpływ na sposób zarządzania zasobami ludzkimi, zatrudniania pracowników, zarządzania finansami, itp. ${ }^{11}$. Do tego zestawu należało by jeszcze dodać większą złożoność wpływów otoczenia, większą otwartość na te wpływy, funkcjonowanie w mniej stabilnym

10 A. Proszkowska, Ksztattowanie kultury międzynarodowej organizacji procesowej, w: Podejście procesowe $w$ organizacjach, red. S. Nowosielski, Wydawnictwo Uniwersytetu Ekonomicznego we Wrocławiu, Wrocław 2011.

11 B. Kożuch, Problemy zarzqdzania organizacjami publicznymi, Fundacja współczesne zarządzanie oraz Instytut spraw Publicznych, Kraków, 2006, cytuję za: K. Krukowski, M. Siemiński, Proces ksztattowania kultury organizacyjnej w organizacji publicznej, „Współczesne Zarządzanie" 2011, nr 3. 
otoczeniu oraz mniejszą presję ze strony konkurentów ${ }^{12}$. Wspomniana złożoność jest między innymi konsekwencją dwojakiej roli pełnionej przez obywateli: podporządkowanej (jako podatnicy) i nadrzędnej (jako usługobiorcy) w stosunku do urzędów. Ten swoisty dualizm ma swe implikacje w postrzeganiu klienta przez urzędników. Klienta, który jest beneficjentem, czyli otrzymuje usługę w formie płatności lub zasiłku, użytkownikiem, kiedy nie ma alternatywnego miejsca korzystania z danej usługi, użytkownikiem i współtwórcą, co oznacza, że jednocześnie może korzystać z usługi i ją świadczyć, nabywcą, czyli użytkownikiem płacącym za realizację danej usługi, podatnikiem, z jasno określonymi obowiązkami w stosunku do państwa, obywatelem i musi przestrzegać zasad, podlega kontroli, ale jednocześnie posiada elementarne prawa zagwarantowane przez państwo, klientem i może wybierać placówkę, z usług której chce korzystać (np. państwowa lub prywatna) ${ }^{13}$.

Szczyt popularności zarządzania procesowego w sektorze prywatnym przypada mniej więcej na połowę lat dziewięćdziesiątych ubiegłego wieku ${ }^{14}$, wtedy również pojawiły się pierwsze artykuły dedykowane tej koncepcji w sektorze publicznym. Niemniej jednak zarządzaniu procesowemu w sektorze publicznym poświęcono zdecydowanie mniej uwagi niż tejże koncepcji w sektorze prywatnym. Te nieliczne, które powstały, koncentrowały się na przeprojektowaniu struktury organizacyjnej z funkcjonalnej na procesową ${ }^{15}$, identyfikacji ${ }^{16}$, optymalizacji ${ }^{17}$, efektywności ${ }^{18}$, wyznaczeniu właścicieli ${ }^{19}$ procesów, powiązaniu

12 B. Kożuch, Zarzqdzanie publiczne $w$ teorii $i$ praktyce polskich organizacji, Placet, Warszawa, 2004, cytuję za: K. Krukowski, M. Siemiński, Proces ksztattowania kultury organizacyjnej w organizacji publicznej, „Współczesne Zarządzanie” 2011, nr 3.

13 D. Shand, M.Arnberg, Background paper; in: OECD; Responsive Government Service Quality Initiatives; Paris 1996.

14 C. Houy, P. Fettke, P. Loos, Empirical research in business process management-analysis of an emerging field of research, "Business Process Management Journal" 2010, nr 4.

15 T.R. Gulledge Jr, R.A. Sommer, Business process management: public sector implications, "Business Process Management Journal" 2002, nr 2.

16 F.O. Sentanin, F.C.A. Santos, Ch. J. Ch. Jabbour, Business process management..., op.cit.

17 M. Hesson, Business process reengineering in UAE public sector, "Business Process Management Journal" 2007, nr 5.

18 C.J. Coulson-Thomas, Process management in a hospital and healthcare context, "Business Process Management Journal” 1997, nr 2; R. MacIntosh, BPR: alive and well..., op. cit.

19 E. Ongaro, Process management in the public sector, "The International Journal of Public Sector Management" 2004, nr 1. 
ich z narzędziami IT $^{20}$, zwróceniu uwagi na perspektywę klienta ${ }^{21}$, wpływie zewnętrznych czynników na implementację zarządzania procesowego ${ }^{22}$.

Za wprowadzeniem $\mathrm{w}$ administracji publicznej zarządzania procesowego przemawia potrzeba zrozumienia aktualnego stanu potrzeb klientów oraz próba rozpoznania nowych stanów wynikających ze zmian potrzeb obywateli lub wymogów prawa ${ }^{23}$. Nie są to jednak jedyne argumenty. Istotne są również elementy świadczące o niesprawności podejścia funkcjonalnego ${ }^{24}$, będącego przeciwieństwem podejścia procesowego, przejawiające się $w$ chęci zaspokojenia wymagań kierownika, który przydziela zadania i egzekwuje ich wykonanie według ściśle wyznaczonych procedur. Może to w konsekwencji prowadzić do przesuwania się poczucia odpowiedzialności ze skutków działania na sposób działania, a zgodność działania z instrukcjami uważana jest za wystarczającą rękojmię sprawności ${ }^{25}$. Powstała w ten sposób biurokracja generuje depersonalizację relacji międzyludzkich spowodowaną sformalizowaną komunikacją i specyficzną nadrzędnością pieczątek i podpisów na dokumentach, nad ludźmi i ich rzeczywistymi problemami, a także organizacją jako całością ${ }^{26}$. Sprowokować to może tzw. postawy lokalne oznaczające koncentrowanie się pracowników na sprawach dotyczących tylko i wyłącznie ich pracy, zadania i utratę szerszej perspektywy ${ }^{27}$. Postawa taka może w konsekwencji prowadzić do konserwatyzmu ukierunkowanego na stabilizację i utrwalenie istniejących norm, wartości i wzorów zachowań jako wartości samych w sobie. Od tego momentu to przeszłość jest wyznacznikiem dla przyszłości, a wszelkie zmiany są zjawiskiem niepożądanym ${ }^{28}$.

Z badań realizowanych w 2009 roku na 480 osobowej grupie jednostek, reprezentujących różne sektory i branże działania z całej Polski przez serwis

20 T.R. Gulledge Jr, R.A. Sommer, Business process management..., op. cit.

21 E. Ongaro, Process management..., op. cit.; C.J. Coulson-Thomas, Process management..., op. cit.

22 R. MacIntosh, BPR: alive and well..., op. cit.; M. Helfert, Challenges of business processes management in healthcare, "Business Process Management Journal" 2009, nr 6.

23 K. Krukowski, M. Siemiński, Zarzqdzanie procesowe $w$ administracji publicznej, „Współczesne Zarządzanie”, 2011, nr 1.

24 T.R. Gulledge Jr, R.A. Sommer, Business process management..., op. cit.

25 Cz. Sikorski, Wolność w organizacji, Oficyna Wydawnicza Antykwa, Kluczbork-Łódź 2000.

26 M. Kołodziejczak, Społeczno-kulturowe aspekty wdrażania orientacji procesowej w organizacjach, w: Podejście procesowe w organizacjach, red. S. Nowosielski, Wydawnictwo Uniwersytetu Ekonomicznego we Wrocławiu, Wrocław 2011.

27 Cz. Sikorski, Ksztattowanie kulturyorganizacyjnej: filozofia, metody, strategie, Wydawnictwo Uniwersytetu Łódzkiego, Łódź 2009.

28 M. Kołodziejczak, Społeczno-kulturowe aspekty..., op. cit. 
PROCESOWCY.PL wynika, iż poziom dojrzałości procesowej dużej części (38\%) polskich organizacji oceniany według nieznacznie zmodyfikowanej hierarchii CMMI (Capability Maturity Model Integration), jest średnio zaawansowany. Oznacza to pełną świadomość zachodzących w organizacjach procesów oraz zdefiniowany system pomiarowy, które nie przekładają się na decyzje zarządcze. Procesy nie dają wymiernej korzyści w postaci odpowiedzi na pytanie o realizację celów strategicznych. Zaledwie 7\% ankietowanych jednostek świadomie identyfikuje, mierzy i zarządza swoimi procesami. We wspomnianym badaniu $19 \%$ ankietowanych stanowiły podmioty sektora publicznego. Poziom ich dojrzałości procesowej jest niższy, niż to wynika z średniej dla Polski. Wśród ankietowanych jednostek sektora publicznego nie znalazła się żadna świadomie identyfikująca, mierząca i zarządzająca swoimi procesami. W jednostkach tych procesy są co najwyżej zidentyfikowane ${ }^{29}$.

Organizacja procesowa wpływa na kształt relacji międzyludzkich, w konsekwencji czego mogą się one kształtować odmiennie, aniżeli w organizacjach zorientowanych funkcjonalnie o silnie zhierarchizowanej strukturze. Dlatego właśnie przechodzenie od organizacji funkcjonalnej do organizacji procesowej powinno być poprzedzone świadomym i przemyślanym kształtowaniem kultury organizacyjnej, jeśli tego nie zrobimy nasza organizacja nigdy nie osiągnie pełni korzyści, jaki niesie ze sobą zarządzanie procesowe ${ }^{30}$. Odpowiednio kształtowana kultura organizacyjna może być katalizatorem zmian organizacyjnych. Rekonstruowanie kultury organizacyjnej oznacza jej rozpoznawanie, analizowanie, projektowanie, wdrożenie oraz monitorowanie w celu wzmocnienia procesów, które realizują poszczególne zamierzenia danej organizacji ${ }^{31}$. Skuteczność tej rekonstrukcji jest uzależniona od jej głębokości. Najbardziej klasyczny model kultury organizacyjnej zaproponowany przez E. Scheina przedstawia ją jako górę lodową i akcentuje jej poziomy. Zmiana na najwyższym poziomie, czyli na poziomie artefaktów ma charakter pozorny i nietrwały, dopiero dotarcie do głębszych warstw zapewnia jej trwałość.

Zmianę kultury organizacyjnej można określić jako proces konstruktywnego konfrontowania dylematów dnia dzisiejszego z wizją organizacji. Polega na osadzaniu pożądanych wartości w procedurach, systemach, procesach oraz instrumentach zarządzania. Jest to możliwe, ale tylko i wyłącznie dzięki wyko-

\footnotetext{
29 Dojrzałość procesowa polskich organizacji, Marzec 2010, http://procesowcy.pl/index. php?option=com_content\&view=article\&id=85\&Itemid=75, dostęp 10-2012

30 T.R. Gulledge Jr, R.A. Sommer, Business process management..., op. cit.

31 M. Czerska, Zmiana kulturowa w organizacji. Wyzwania dla wspótczesnego menedżera, Difin, Warszawa, 2003.
} 
rzystaniu wiedzy i inteligencji wszystkich pracowników, mobilizując pomysłowość i inne potencjały do budowania organizacji procesowej ${ }^{32}$.

\section{Procesowo zorientowana kultura organizacyjna}

Kultura, mimo iż jest koncepcję szeroko definiowaną pozostaje niejednoznaczną z uwagi na zainteresowanie nią przedstawicieli wielu nauk między innymi socjologów, antropologów, psychologów. W 1952 roku C. Kreober oraz A. Kluckhon zidentyfikowali ponad 150 sposobów definiowania kultury ${ }^{33}$. Niemniej jednak do najbardziej popularnych definicji kultury organizacyjnej należą: zaproponowana przez G. Hofstede utożsamiająca kulturę z kolektywnym zaprogramowaniem umysłu ${ }^{34}$ oraz E. Scheina który kładzie nacisk na uczenie się kultury poprzez wytyczne dostarczane przez grupę, a dotyczące podstawowych założeń ${ }^{35}$.

Kultura organizacyjna jest tworem społecznym, koncepcją miękką, trudną do zmiany, jest holistyczna, zdeterminowana historycznie, powiązana z przedmiotowymi badaniami antropologicznymi ${ }^{36}$, dlatego można jedynie określić wymogi, które w dłuższej perspektywie czasowej mogą wywierać wpływ na kształt relacji wewnątrzorganizacyjnych. Przeglądu artykułów poświęconych kulturze organizacyjnej $\mathrm{w}$ organizacji procesowej dokonali J. Brocke oraz T. Sinnl. Zidentyfikowane 572 artykuły skategoryzowali według dwóch kryteriów:

- grupy odniesienia (kultura zespołu (grupy roboczej), kultura organizacyjna, kultura narodowa),

- zależności pomiędzy kulturą a BPM (kultura jako czynnik niezależny wpływający na BPM, kultura jako czynnik zależny kształtowany przez BPM, kultura jako kultura BPM) $)^{37}$.

Zaproponowali oni również, aby dochodzenie do pożądanego kształtu kultury w organizacji procesowej przebiegało od najwyższego kierownictwa, którego zaangażowanie będzie wsparciem dla kolejnego etapu, jakim powinno być przeprojektowanie struktury organizacyjnej, prowadzące w konsekwencji do zmiany aktywności poszczególnych pracowników, oraz zmiany systemu warto-

\footnotetext{
32 P. Grajewski, Procesowe zarzadzanie..., op. cit.

33 J. Brocke, T. Sinnl, Culture in business process management..., op. cit.

34 G. Hofstede, Kultury i organizacje, Polskie Wydawnictwo Ekonomiczne, Warszawa 2007.

35 J. Brocke, T. Sinnl, Culture in business process management..., op. cit.

36 M. Czerska, Zmiana kulturowa w organizacji, Difin, Warszawa 2003, s. 12.

37 J. Brocke, T. Sinnl, Culture in business process management..., op. cit.
} 
ści w organizacji. Autorzy stworzyli w ten sposób triadę kultury organizacyjnej korespondującą $\mathrm{w}$ sposób bezpośredni z poziomami kultury organizacyjnej zaproponowanymi przez E. Scheina

Rysunek 1. Kultura organizacji procesowej

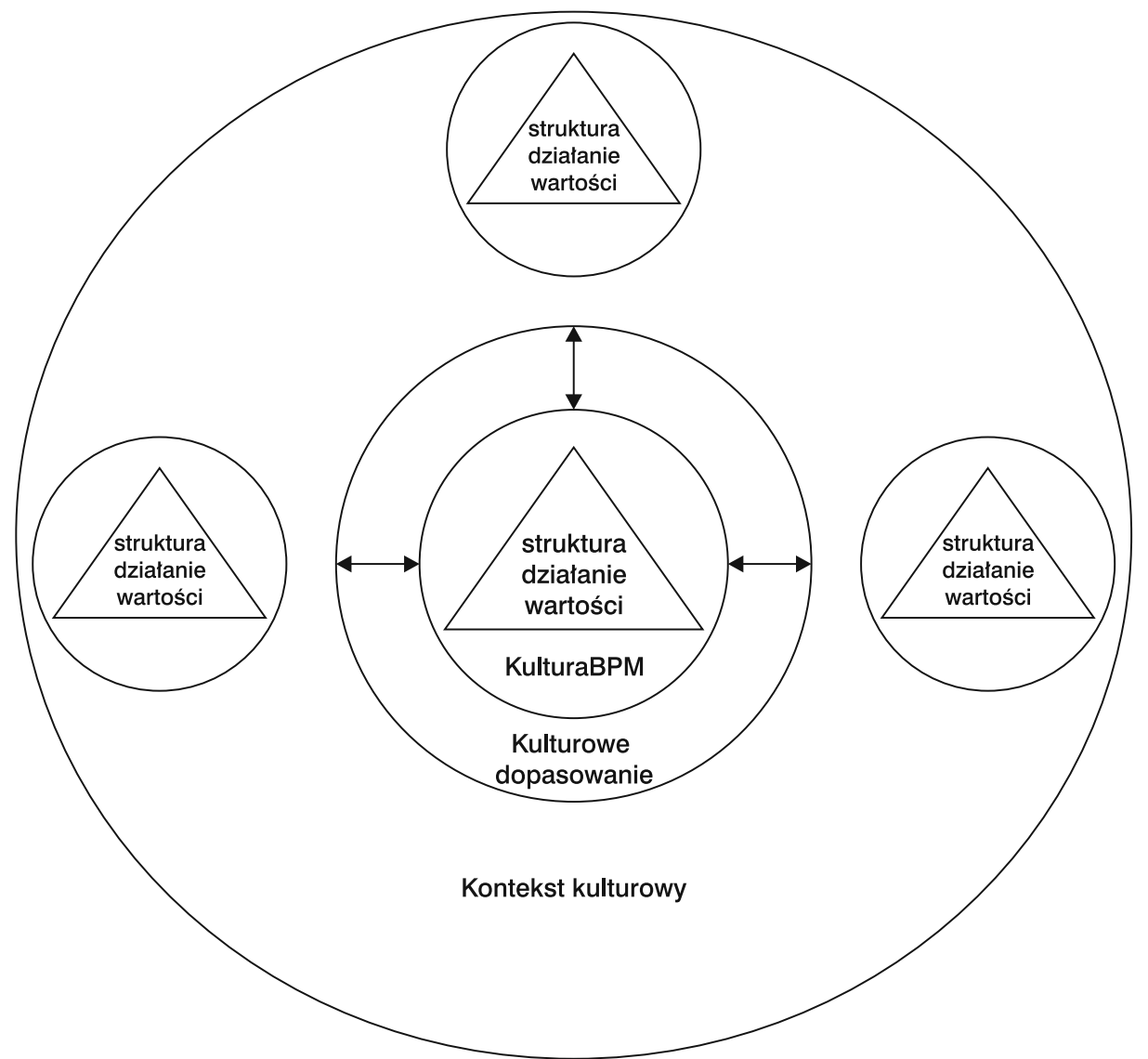

Źródło: J. Brocke, T. Sinnl, Culture in business process management..., op. cit.

Analiza artykułów dotyczących kultury organizacyjnej w BPM potwierdziła wnioski P. Grajewskiego dotyczące kulturowych wymogów organizacji procesowej. Należą do nich:

- chęć ciągłego uczenia się i dążenie do pogłębiania wiedzy,

- dzielenie się informacją, swobodny jej przepływ przez wszystkie obszary,

- otwarta dyskusja i wymiana poglądów,

- profesjonalizm i samodzielność w działaniu,

- partnerstwo i zdolność do negocjacji, 
- duże poczucie własnej wartości wśród pracowników,

- dobre relacje interpersonalne,

- rozwój osobisty pracowników,

- orientacja na klienta,

- elastyczność i pozytywne nastawienie do zmian,

- orientacja na przyszłość i akceptacja zmian o charakterze radykalnym ${ }^{38}$.

Taka kultura organizacyjna prowadzi do bardzo istotnej w organizacji perspektywy „my” będącej konsekwencją wspólnego celu i wspólnych wartości, wzajemnej akceptacji oraz dawania sobie prawa do popełniania błędów w określonych granicach.

Na tej podstawie M. Sznabowicz proponuje cechy kultury w organizacji procesowej:

- na poziomie artefaktów - integrowanie pracowników w ramach organizowanych spotkań okolicznościowych oraz szkoleń i seminariów, relacje międzyludzkie przyjazne, partnerskie, otwarte i raczej nieformalne, pracownicy często wymieniający się poglądami z przełożonymi, a także klientami i dostawcami, wysoki stopień informatyzacji,

- na poziomie norm i wartości - innowacyjność, praca zespołowa, dzielenie się wiedzą, otwarta komunikacja, profesjonalizm członków zespołów, wysoka jakość produktów i usług, lojalność wobec firmy i klientów, zaangażowanie w sprawy firmy, ciągłe doskonalenie,

- na poziomie podstawowych założeń - człowiek jako najważniejszy zasób organizacji, ciągłe doskonalenie jako warunek rozwoju organizacji, partnerstwo oraz osobiste zaangażowanie członków, główne źródła władzy w organizacji to odniesienie oraz autorytet eksperta, większe znaczenie ma status osiągnięty ${ }^{39}$.

Dzięki zaprojektowaniu takiej kultury organizacyjnej łatwiejsze staje się katalizowanie pożądanych zachowań organizacji procesowej. Kultura jest istotnym instrumentem mogącym kształtować zachowania ludzi. Kultury uczymy się poprzez socjalizację, $\mathrm{w}$ ten sposób społeczności oddziałuje na jednostkę i egzekwuje przyjęte przez nią normy i wartości. Osoby, które je przyswoiły nie wymagają ścisłej kontroli, ich produktywność jest wynikiem samoukierunkowania, inicjatywy i emocjonalnego zorientowania na rozwój przedsiębiorstwa $^{40}$. Z badań przeprowadzonych przez Somerville K., Elliott, C. wśród

38 P. Grajewski, Procesowe zarzqdzanie..., op. cit.

39 M. Sznabowicz, Stan i kierunki doskonalenia kultury organizacji procesowych, Sopot, 2011, cytuję za: P. Grajewski, Procesowe zarzqdzanie..., op. cit., s. 114-115

40 P. Grajewski, Procesowe zarzadzanie..., op. cit. 
jednostek sektora publicznego o najwyższym poziomie obsługi klienta, wynika iż jednym z najważniejszych czynników determinujących poprawę satysfakcji klientów jest właściwa kultura organizacyjna. Tę „właściwość” można ocenić z perspektywy procesu komunikacji wewnętrznej i zewnętrznej, w której szczególny nacisk kładzie się na sprzężenie zwrotne i nieustanne poszukiwanie sposobów poprawy. Większej satysfakcji klienta sprzyja natomiast innowacyjność i otwartość na nowe pomysły, zaufanie, kolegialność, upodmiotowienie i właściwe podejmowanie ryzyka ${ }^{41}$. Do podobnych wniosków doszli w 2009 roku W. Bandara, A. Alibabaei i M. Aghdasi ${ }^{42}$. Siobhan Corrigan zidentyfikował, iż czynnikami wpływającym na porażkę zarządzania procesowego, a wynikającymi z barier kulturowych są funkcjonalna struktura organizacyjna, wertykalny system komunikacji i utożsamianie systemu IT w organizacji jako źródła wszelkiego zła ${ }^{43}$. Badania litewskiego zespołu J. Ruževičius, D. Klimas i R. Veleckaitė pokazały, iż kulturą dominującą wśród jednostek organizacyjnych litewskiego sektora publicznego jest kultura hierarchii, pochodząca z typologii zaproponowanej przez Camerona i Quinna ${ }^{44}$. Charakteryzująca się ścisłą hierarchią i formalizacją działań, gdzie przywódcy pełnią role koordynatorów i organizatorów nastawionych na efektywność, a zarządzanie pracownikami skupia się na bezpieczeństwie, zapewnieniu stałości i przewidywalności. W takiej kulturze organizacyjnej najważniejsze jest sprawne funkcjonowanie organizacji, osiągane dzięki jej formalnym przepisom i regulaminom ${ }^{45}$. Kulturze takiej daleko do spełnienia wymogów kultury procesowej. $\mathrm{Z}$ obserwacji autorek wynika, iż duża część jednostek administracji publicznej w Polsce również posiada cechy kultury hierarchii. Do podobnych wniosków dochodzi R. Wolniak. Z przeprowadzonych przez niego w latach 2006-2007 badań wynika, iż decyzje w jednostkach sektora publicznego podejmowane są w sposób autorytarny, poziom akceptacji ryzyka jest przeciętny, stosunek do zmian ambiwalentny, nadmierne

41 K. Somerville , C. Elliott, Strategies to improve client service: Exemplars in the Canadian federal government, "The Innovation Journal: The Public Sector Innovation Journal" 2011, nr 2.

42 W. Bandara, A. Alibabaei, M. Aghdasi, Means of achieving business process management success factors, MCIS 2009 Proceedings of the 4th Mediterranean Conference on Information Systems, Athens, Greece, 25-27 September 2009, http://eprints.qut.edu.au/, dostęp 10-2011.

43 S. Corrigan, Human and Organizational Aspects of Business Process Reengineering, Institute of Work Psychology, University of Sheffield, http://faculty.css.edu/dswenson/web/ REENGIN.HTM, dostęp 10-2012

44 J. Ruževičius, D. Klimas, R. Veleckaite, Influence of organizational culture on the success of business process management in Lithuanian public sector organizations, "Current Issues of Business and Law" 2012, nr 1.

45 K.S. Cameron, R.E. Quinn, Kultura organizacyjna - diagnoza i zmiana. Model wartości konkurujacych, Oficyna Ekonomiczna, Kraków 2006. 
znaczenie przypisuje się formalnej władzy i formalnym tytułom, natomiast mało jest miejsca pozostaje na kreatywność pracowników ${ }^{46}$.

\section{Podsumowanie}

W artykule przedstawiono przegląd literatury dotyczącej zarządzania procesowego. Starano się przytaczając argumenty pochodzące zarówno z analiz empirycznych jak i teoretycznych pokazać, iż pierwszym etapem realizacji zarządzania procesowego powinno być świadome zaprojektowanie kultury organizacyjnej, opierającej się na skutecznej, wielokierunkowej komunikacji i nieustannym doskonaleniu. Właściwie zaprojektowana kultura w organizacji procesowej powinna katalizować zmianę perspektywy patrzenia na świat z wertykalnej na horyzontalną i dzięki temu wzmocnić zaangażowanie obywateli zarówno na poziomie rządu, jak i samorządu. Przykładem włączania obywateli w proces rządzenia mogą być między innymi demokracja deliberatywna, e-demokracja, publiczny dialog, budżetowanie partycypacyjne, panele obywatelskie, rady obywatelskie, grypy studyjne, grupy focusowe, okrągły stół, specjalistyczne rady doradcze, nowe formy zebrań miejskich i inne formy partnerskiego porozumienia ${ }^{47}$.

Poziom zaawansowania zarządzania procesowego w jednostkach administracji publicznej oraz przytoczone wyniki nielicznych badań pokazują jak wiele jest jeszcze do zrobienia na tym polu.

\section{Bibliografia}

Brocke J., Sinnl T., Culture in business process management: a literature review, "Business Process Management Journal" 2011, nr 2.

Cameron K.S., Quinn R.E., Kultura organizacyjna - diagnoza i zmiana. Model wartości konkurujących, Oficyna Ekonomiczna, Kraków 2006.

Coulson-Thomas C.J., Process management in a hospital and healthcare context, “Business Process Management Journal” 1997, nr 2.

46 R. Wolniak, Wymiary kulturowe organizacji publicznych, „Współczesne Zarządzanie” 2008, nr 2.

47 L. Blomgren Bingham, R. O'Leary, T. Nabatchi, Legal Frameworks for the New Governance: Processes for Citizen Participation in the Work of Government, "National Civic Review”, Spring 2005, s. 54-61; E. Bacia, Analiza metodologii i głównych wyników badań dotyczqcych partycypacji obywatelskiej. Materiał roboczy, http://partycypacjaobywatelska.pl/publikacje/ kategoria/3 dostęp 10-2012. 
Czerska M., Zmiana kulturowa w organizacji. Wyzwania dla wspótczesnego menedżera, Difin, Warszawa 2003.

Grajewski P., Procesowe zarzadzanie organizacja, Polskie Wydawnictwo Ekonomiczne, Warszawa 2012.

Gulledge T.R. Jr, Sommer R.A., Business process management: public sector implications, "Business Process Management Journal” 2002, nr 2.

Helfert M., Challenges of business processes management in healthcare, "Business Process Management Journal" 2009, nr 6.

Heracleous L., Johnston R., Can business learn from the public sector?, "European Business Review" 2009, nr 4.

Hesson M., Business process reengineering in UAE public sector, "Business Process Management Journal" 2007, nr 5.

Hofstede G., Kultury i organizacje, Polskie Wydawnictwo Ekonomiczne, Warszawa 2007.

Houy C., Fettke P., Loos P., Empirical research in business process management - analysis of an emerging field of research, "Business Process Management Journal" 2010, nr 4.

Jeston J., Nelis J., Management by Process: A Roadmap to Sustainable Business Process Management, Elsevier, Oxford 2008.

Kołodziejczak M., Społeczno-kulturowe aspekty wdrażania orientacji procesowej $w$ organizacjach, w: Podejście procesowe $w$ organizacjach, red. S. Nowosielski, Wydawnictwo Uniwersytetu Ekonomicznego we Wrocławiu, Wrocław 2011.

Kożuch B., Problemy zarzqdzania organizacjami publicznymi, Fundacja Współczesne Zarządzanie oraz Instytut spraw Publicznych, Kraków 2006.

Kożuch B., Zarzadzanie publiczne $w$ teorii i praktyce polskich organizacji, Placet, Warszawa 2004.

Krukowski K., Siemiński M., Zarzqdzanie procesowe $w$ administracji publicznej, „Współczesne Zarządzanie” 2011, nr 1.

MacIntosh R., BPR: alive and well in the public sector, "International Journal of Operations \&, Production Management” 2003, nr 3.

Ongaro E., Process management in the public sector, "The International Journal of Public Sector Management" 2004, nr 1.

Proszkowska A., Kształtowanie kultury międzynarodowej organizacji procesowej, w: Podejście procesowe $w$ organizacjach, red. S. Nowosielski, Wydawnictwo Uniwersytetu Ekonomicznego we Wrocławiu, Wrocław 2011.

Ruževičius J., Klimas D., Veleckaitè R., Influence of organizational culture on the success of business process management in Lithuanian public sector organizations, "Current Issues of Business and Law" 2012, nr 1.

Sentanin F.O., Santos F.C.A., Jabbour Ch.J.Ch, Business process management in a Brazilian public research centre, "Business Process Management Journal" 2008, nr 4.

Shand D., Arnberg M., Background paper; in: OECD; Responsive Government Service Quality Initiatives; Paris 1996.

Sikorski Cz., Kształtowanie kultury organizacyjnej: filozofia, metody, strategie, Wydawnictwo Uniwersytetu Łódzkiego, Łódź 2009. 
Sikorski Cz., Wolność w organizacji, Oficyna Wydawnicza Antykwa, KluczborkŁódź 2000.

Somerville K., Elliott C., Strategies to improve client service: Exemplars in the Canadian federal government, "The Innovation Journal: The Public Sector Innovation Journal" 2011, nr 2.

Sznabowicz M., Stan i kierunki doskonalenia kultury organizacji procesowych, Sopot 2011.

Wolniak R., Wymiary kulturowe organizacji publicznych, „Współczesne Zarządzanie” 2008, nr 2.

\section{Strony internetowe:}

Dojrzałość procesowa polskich organizacji, Marzec 2010, http://procesowcy.pl/index. php?option $=$ com_content\&view $=$ article $\& i d=85 \& I t e m i d=75$, dostęp 10-2012

Corrigan S., Human and Organisational Aspects of Business Process Reengineering, Institute of Work Psychology, University of Sheffield, http://faculty.css.edu/ dswenson/web/REENGIN.HTM, dostęp 10-2012

Bandara W ., Alibabaei A., Aghdasi M., Means of achieving business process management success factors, MCIS 2009 Proceedings of the 4th Mediterranean Conference on Information Systems, Athens, Greece, 25-27 September 2009, http://eprints.qut.edu.au/, dostęp 10-2012

\section{Summary \\ Process Oriented Organizational Culture in Public Sector Organizations}

The process approach to organization management is based on the assumption that things are organized into sets of collective and interlinked activities that aim to generate value, which is attractive to a consumer ${ }^{48}$. This approach is an alternative to the functional model of organization. In public sector institutions, an autonomy of particular areas within expanded structures often takes place. It is called ,the silo effect': particular departments are not focused on understanding customer's current needs and on supplying adequate service, but on securing their own, internal interests. This may result in extending time needed to carry out the contracts, in cost increase as well as in decrease in flexibility of organization.

Keywords: organizational culture, process management, public sector.

\footnotetext{
48 P. Grajewski, Procesowe zarzadzanie..., op. cit.
} 


\section{Резюме}

\section{Процессуально-ориентированная организационная культура в организациях публичного сектора}

Процессуальный подход к управлению организацией связан с восприятием вещей, организованных как наборы коллективных действий, связанных друг с другом таким образом, чтобы в их результате возникла привлекательная для покупателя ценность. Это альтернатива функциональной модели организации. В субъектах публичного сектора неоднократно случается, что разросшаяся организационная структура ведет к автономизации отдельных областей в рамках этой структуры, что называется эффектом „силосных башен”. Отдельные отделы не сосредоточиваются на понимании клиента и предоставлении ему услуги, соответствующей его актуальным потребностям, но обеспечивают свои внутренние интересы. Это может вести к замедлению темпов реализации контрактов, увеличению расходов на деятельность и снижению гибкости фирмы.

Ключевые слова: организационная культура, процессуальное управление, публичный сектор.

\section{Dr inż Liliana Hawrysz}

Adiunkt w Katedrze Organizacji i Zarządzania Politechniki Opolskiej. Tytuł doktora nauk ekonomicznych z zakresu zarządzania uzyskała na Politechnice Warszawskiej na Wydziale Inżynierii Produkcji. Jej zainteresowania naukowe koncentrują się wokół tematyki zachowań organizacyjnych ze szczególnym uwzględnieniem przywództwa, motywacji i zaangażowania organizacyjnego, kultury organizacyjnej oraz zarządzania w sektorze publicznym. Prowadzi zajęcia dydaktyczne z zachowań organizacyjnych, kultury organizacyjnej, koncepcji zarządzania oraz podstaw zarządzania na studiach licencjackich i magisterskich. Od 2009 roku regularnie prowadzi praktykę dydaktyczną na Uczelniach Europejskich, m. in. w Hiszpanii (Walencja), Danii (Kopenhaga), Czechach (Praga) i na Litwie (Wilno).

\section{Dr inż. Katarzyna Hys}

Adiunkt w Katedrze Inżynierii Jakości Produkcji i Usług Politechniki Opolskiej. Tytuł doktora nauk ekonomicznych $\mathrm{z}$ zakresu zarządzania uzyskała na 
Politechnice Warszawskiej na Wydziale Inżynierii Produkcji. Jej zainteresowania naukowe koncentrują się wokól tematyki zarządzania organizacją, ze szczególnym uwzględnieniem jakości, usług, społecznej odpowiedzialności oraz marketingu. Prowadzi zajęcia dydaktyczne z zarządzania jakością usług, zarządzania jakością produkcji, marketingu na studiach inżynierskich. Od 2009 roku regularnie prowadzi praktykę dydaktyczną na Uczelniach Europejskich, m. in. w Hiszpanii (Walencja), Danii (Kopenhaga), Czechach (Praga), na Litwie (Wilno). 
